\title{
Human Resources Information System (HRIS): A Theoretical Perspective
}

\author{
Sabrina Jahan \\ The People's University of Bangladesh, Dhaka, Bangladesh \\ Email: ibne.rashed@gmail.com
}

Received 2 April 2014; revised 6 May 2014; accepted 15 May 2014

Copyright (C) 2014 by author and Scientific Research Publishing Inc. This work is licensed under the Creative Commons Attribution International License (CC BY). http://creativecommons.org/licenses/by/4.0/

(c) (i) Open Access

\begin{abstract}
HRIS is one of the major modern HR tools. In developed countries, it became popular since the beginning of this century. In Bangladesh, corporate organizations have started to implement HRIS in last 5 years. But still its implementation is limited within the big corporate houses. Small corporate houses and public organizations have failed to realize the benefits of HRIS and taken hardly any initiative to implement the system. The major barrier to success of HRIS is the lack of management commitment. The major limitation is the high cost. But the benefits of the HRIS are more than the limitations. Once it is implemented in any organization, employees and management have accepted and realized the benefits. But to get it implemented is a challenge. This study is an attempt to provide a theoretical analysis of the HRIS implementation with analysis of benefits, limitations and barriers. A case study was prepared to provide a better understanding of the topic in a real life context.
\end{abstract}

\section{Keywords}

HRIS, HR Tools

\section{Introduction}

Human Resource Information System (HRIS) is a systematic way of storing data and information for each individual employee to aid planning, decision making, and submitting of returns and reports to the external agencies. HRIS can be briefly defined as integrated systems used to gather, store and analyze information regarding an organization's human resources [1].

It merges HRM as a discipline and in particular it's basic HR activities and processes with the information technology field. It can be used to maintain details such as employee profiles, absence reports, salary administration and various kinds of reports. It is one of the benchmark HR practices in the corporate world. In Bangla- 
desh the importance of HRIS is being felt by the HR professionals and entrepreneurs.

The professionals and entrepreneurs are realizing the importance of a good HR system. HRIS is one of the key components of the HR system. As a result, the importance of HRIS is increasing with the rapid growth of the corporate sectors in Bangladesh. But still there are a lot of barriers to the success of HRIS. One of the major factors is the limited understanding of benefits and cost. It is still difficult to measure the return of investment in HRIS. This study has been initiated to understand the benefits, cost and barriers of HRIS in a theoretical context.

The objectives of the study are as follows

1) Understanding the need of HRIS in modern organizations.

2) Understanding applications \& utilities of HRIS.

3) Understanding benefits of HRIS.

4) Understanding barriers to HRIS.

The main focus of the study is the Human Resource Information Systems in modern organization.

\section{Methodology}

\subsection{Primary Source}

Primary data have been collected from interview with HR professionals, HR managers, and HRIS officers, software developers of different local and multinational organizations. They have provided a lot of insights and information regarding HRIS.

\subsection{Secondary Source}

Secondary data have been collected from different books, journals and articles on HRIS.

\subsection{Form of Data Collection}

Data collection was mainly based on material study and interview since it is a qualitative work. The respondents are mainly HR professionals, HR managers, and HRIS officers, software developers of different local and multinational organizations. No structured questionnaire was used in the interview. The concerned people were asked tell about their experience with HRIS in terms of benefits, challenges, application and need.

\subsection{Limitation of Data Collection}

There are limited study materials on the HRIS in the context of Bangladesh.

\section{Application \& Utilities}

A standard HRIS has the following applications and utilities [2].

- People administration.

- Payroll.

- Compensation and benefit.

- Leave and absence.

- Performance evaluation.

- Recruitment.

- Personal self service.

- Training \& development.

\section{Benefits}

The conversion process often presents opportunities to streamline business processes, improve procedures and cut HR costs. With planning, you can have a painless conversion-and, as an end result, a more efficient, more accurate HRIS [3].

The key benefits of HRIS are as follows [4].

- Higher Speed of retrieval and processing of data.

- Reduction in duplication of efforts leading to reduced cost. 
- Ease in classifying and reclassifying data.

- Better analysis leading to more effective decision making.

- Higher accuracy of information/report generated.

- Fast response to answer queries.

- Improved quality of reports.

- Better work culture.

- Establishing of streamlined and systematic procedure.

- More transparency in the system.

- Employee-Self Management.

\section{Limitations}

The limitations of HRIS are as follows [4].

- It can be expensive in terms of finance and manpower.

- It can be threatening and inconvenient.

- Thorough understanding of what constitutes quality information for the user.

- Computer cannot substitute human beings.

\section{Challenges to Success of HRIS}

The challenges to success of HRIS are as follows [5].

- An inconsistency in the importance attributed to HRIS resulting in difficulties in sustaining management commitment to the project and in obtaining the resources necessary to fully develop the new or upgraded HRIS.

- A tendency to underestimate the complexity of the HRIS and its impact on the behavior and processes of the organization.

- The barriers to user acceptance of the HRIS and the consequent underestimation of the importance of change management.

\section{Steps to Be Followed in Implementing HRIS}

The following steps are involved in developing and implementing an HRIS [6].

Step 1. Inception of idea

The first step of HRIS implementation is the inception of the idea. The need of the organization to have HRIS software must be realized and agreed by the top management. It is an investment and management needs to keep it in mind.

Step 2. Feasibility study

As this is an investment the feasibility of HRIS must be assessed. It covers the following areas

- Scope of the software

- Future benefits after implementation

- Potential software developers assessment

- Cost estimate

- Value addition to business

- ROI calculation

A proper feasibility study will help the management to make the decision based on facts and figures.

Step 3. Selecting a project team

Implementation of HRIS is a project as it requires ensuring budgeted cost, specific timeline with quality delivery. Successful implementation largely depends on capability and effort of project team. Project team members should be taken from both HR and IT. Involvement of senior managers is required to get the top management buy in on different issues. "Experts recommend that HR and IT representatives share leadership of the project team. If at all possible, project team leaders should be dedicated to conversion full time. "Having a dedicated team means [the implementation] will go faster," says Gretchen Alarcon, vice president of human capital management product strategy for the Redwood Shores, Calif-based HRIS software firm Oracle" [3].

Step 4. Defining the requirements 
At this stage the scope needs to be defined. It will not be a detailed requirement specification but at least the processes that will be incorporated in the software. Some organization may want to develop the payroll module while others may want more modules to be developed. It all depends on the affordability and plan of the concerned organization. But it is an essential step before communicating with the vendor or software developers. Otherwise it will create complexity during discussion and negotiation with the software developers. At this stage the company HR policies and processes must be analyzed and defined rigorously. If there is any ambiguity in process, difficulty may arise to incorporate it in the software.

Step 5. Vendor analysis

Selecting the right software developer is another challenge. The capability, track record and good will of the developers must be taken into consideration. The requirement of the organization must be shared with the developers clearly without ambiguity. The existing processes can be clarified with them, if required. After getting clear understanding about the requirement they will come up with their offer that includes cost and specific timeline for project completion. The software requirement specification needs to be documented to avoid ambiguity in future.

Step 6. Package contract negotiation

After getting the final offer from the vendors, the decision of work order will be finalized based on cost and quality actors. Then the contract will be signed with the software developers. The development work will start then. But the company needs to monitor the development work time to time to ensure on time quality delivery of the project.

Step 7. Training

Training usually begins as soon as possible after the contract has been signed. First, the members of the project team are trained to use the Human Resource Information System. Toward the end of the implementation, the human resource representation will train managers from other departments in how to submit information to the HRIS and how to request information from it.

Step 8. Tailoring the system

After finalizing the system requirement specification, the design of the software will be initiated. The design should be shared with the company to identify improvement areas.

Step 9. Collecting data

At this stage required data to enter in the software will be collected. A team of HR needs to be deployed to collect data for the software. Data validation is also required. This is a very critical part of the project.

Step 10. Testing the system

Once the system is developed with data the testing is required. Some organizations call it User Acceptance Test. At this stage the users use it and try to check if there is any gap between requirement and the delivery of the software. If the test is okay then the final delivery is given to the company.

Step 11. Starting up

After the User Acceptance the software will be installed in user's PC or web as per system configuration and requirement specification.

Step 12. Running in parallel

It is a safe stand to run the existing process whether it is manual or software and the new software run in parallel. In case of any malfunction of the new software the process will not get hampered. At least one full cycle of the process needs to be run in parallel to avoid any technical hitch.

Step 13. Maintenance

Once the software has been installed regular maintenance and performance monitoring is essential. For effectiveness annual maintenance contract can be signed with the software development company.

Step 14. Evaluation

After running the software for a certain period of time the performance evaluation will be done. What value the software has added since its inception needs to be evaluated.

\section{A Case Study}

A large Bangladeshi local organization took HRIS software recently. Before taking the new software a software was in use that had only one module, payroll. The company was much updated in terms of HR processes. But to support the vision of the organization to grow and expand automation of the HR processes was felt rightly by the 
top management. The organization was a group of 13 SBUs where in total 4000 employees were employed. The group had employees spread in almost 50 locations across Bangladesh. Like business portfolios, diversity existed in job nature, people issues and locations. It was a challenge for the group HR to accommodate such. The initial perception was to cater the diversity in terms of location and business needs, make the HR processes faster. It was a business as well as a strategic decision for the company to take the new software. There plan was to cater all the HR processes in the software. When the top management agreed in this regard, a team was formed with participation from both HR and IT. The team decided to go for a customized software instead of a readymade one. They selected a software development firm considering cost, positive track record and goodwill in the market. Despite many challenges, the software was launched within six months since the work order was issued. Some tweaking required later on but the company is satisfied with software considering the benefits they are getting from the software.

The process or steps followed to run the software have been narrated below.

\section{Process/Policy Study}

First, the HR process and policies were analyzed thoroughly. The key HR people sat together to study the HR policies. The gaps or gray areas that might create problem for the software were identified and solved accordingly. Some changes were made in the practices and processes to make alignment with standard system. The team had to work in details.

\section{1) Scope Identification}

Then the scope of the software was identified. HR processes to be incorporated in the software were selected and documented.

\section{2) System Requirement Specification (SRS)}

Based on the scope SRS was prepared in line with HR policies and procedures. For each requirement business rules and corresponding policies were identified. To prepare a detail SRS is required to avoid any kind of confusion and complexity between the company and software developers. It ensures clarity of work as well.

\section{3) Vendor Selection}

A software development company was selected based on comparative analysis in terms cost, experience and goodwill in the market. The SRS was shared with them. It plan was to get a customized software. Based on the SRS the software developers gave a cost estimate. Then the software firm was given the work order to start the development work. Cost was an issue for the organization. After much negotiation the cost and the project completion date was finalized.

\section{4) User Acceptance Test (UAT)}

Before the final delivery of the software a system test was done by the users. The test is called Users Acceptance Test or UAT. At the UAT the software developers presented a demo of the software. It is checked whether there is any gap between the SRS and demo. After couple of UAT the software passed the test.

\section{5) Final Delivery}

Finally the software was delivered but later than the project completion date. The reasons identified for this delay were lack of co-ordination among the two departments HR \& IT and lack of clarity in the SRS.

\section{6) User Training}

The users were imparted training on the software. The success of HRIS software largely depends on the effectiveness of training or communication to end users. The success of the software largely depends on effective use by the users. Training was facilitated in all the 50 locations of the company. It was a huge task that was delivered by the project team.

\subsection{Modules}

Almost all the HR processes were incorporated in the software. The software had two parts web and desktop. In the web part the general users had own account. The modules of the software are as follows.

a) Employee information: Main features of this module were employee database, reporting, organizational structure, joining, transfer and promotion.

b) Recruitment: Main features of the modules are CV bank, recruitment requisition, interview board, record of interview result.

c) Training: Main features of the module are training requisition, training calendar, training record and report.

d) Leave: Main features of the module are leave policy, leave application, leave calendar and reports. 
e) Performance management: Main features of the module are target setting, approval by line managers, performance management process and reporting.

f) Survey: Main features of the module are administering surveys and reports.

g) Payroll: It has catered all the processes under payroll.

h) Attendance: Main features are attendance record and report.

\subsection{Benefits}

1) Faster communication between line manager and individual. The HR related transaction between line manger and individual became faster that resulted in time saving for more value added and strategic works.

2) HR communication became faster. Employees were a click away from HR.

3) Easy storage, retrieval \& reporting of information. Information became readily available in the software. More analysis was possible within a short time. After launching of the software analysis became very easy despite scattered location and employee across the country. Date accuracy was ensured.

4) It saved cost in terms of paper usage. The overall HR department's efficiency improved due to inception of this HRIS software. The organization conducted several surveys without usage of a single sheet of paper.

5) Many HR services were made automated. As a result HR services shifted from a bureaucratic system to a self service system with minimum manual work. The HR processes got faster, more accurate and more efficient than before. It made possible the maximum output with minimum input.

6) It made IT focused and speedy work culture. Before launching of the software many employees were not comfortable in using computer. But the software made a paradigm shift in the organization.

7) It made a shift in HR organization from a traditional to strategy focused. The HR people got opportunity and more time to focus on strategic issues as many administrative services were provided through self service.

\subsection{Reasons of Success}

1) Top management commitment. Top management was very committed and enthusiastic about development of this software. They considered the project as an investment.

2) Effective need analysis. The need analysis was done in an effective way.

3) Inclusion of key people. The key people from HR and IT department were selected for the project team. Like Head of HR, Head of IT and other managers were part of the project team. As a result, better co-ordination, leadership, communication with top management and monitoring were possible.

4) Capable and dedicated project team. The project team was committed to complete the project maintaining time, quality and cost parameters.

5) Effective communication and training to the users. Training of general users made the users more confident in using the software. Confusion regarding the software among users was clarified.

\section{Conclusion}

HRIS is essential for any good organization to ensure effective people management and to get a competitive edge in the corporate world accordingly. In Bangladesh, it is gradually getting popularity and acceptability. The enterprise/business owners should consider it as an investment rather than cost. Commitment of top management is required to remove the existing barriers to success of HRIS. Like MIS, it will help management to make effective and better decision. The communication between individual and line manager became faster. The HR services became self service rather than paper based transaction that resulted in more efficient HR department.

\section{References}

[1] Hendrickson, A.R. (2003) Human Resource Information Systems: Backbone Technology of Contemporary Human Resources. Journal of Labor Research, 24, 381. http://dx.doi.org/10.1007/s12122-003-1002-5

[2] Sah, M.K. (2013) Human Resource Information System. http://www.authorstream.com/Presentation/mundirika10-1428876-hris/

[3] Arnold, J.T. (2007) Moving to a New HRIS. HR Magazine: HR Technology, 52, 6.

[4] Shanu, U. (2013) Human Resource Information Systems. http://www.slideshare.net/ujjmishra1/human-resource-information-system-28839723 
[5] Dery, K., Grant, D. and Wiblen, S. (2013) Human Resource Information Systems (HRIS): Replacing or Enhancing HRM. http://ebookbrowsee.net/hr/hris-replacing-or-enhancing-hrm

[6] Francis, A. (2011) Steps Involved in Developing and Implementing an HRIS.

http://www.upublish.info/Article/Steps-involved-in-developing-and-implementing-an-HRIS/674492 